Article

\title{
'It's a challenge': Post Primary Physical Education Teachers' experiences of and perspectives on inclusive practice with students with disabilities
}

\author{
Ona McGrath ${ }^{1}$, Susan Crawford ${ }^{2}$ and Dan $\mathrm{O}^{\prime}$ Sullivan $^{3}$ \\ Received: 20 August 2018; Accepted: 16 ${ }^{\text {th }}$ December 2018; Published: $1^{\text {st }}$ March 2019
}

\begin{abstract}
Internationally, several studies have indicated insufficient emphasis on the theory and practice of inclusion in relation to disability, in both initial teacher education and continuing professional development programmes for Physical Education (PE) teachers. This has resulted in some negative attitudes and perceived lack of competency among teachers in relation to inclusive practices in PE. There is a lack of in-depth studies in this regard from an Irish perspective. This current study sought to explore seven PE teachers' experiences and perspectives in relation to the inclusion of students with disabilities in four post primary schools using a multiple case study design. Qualitative data was generated from in-depth semi structured interviews. Teachers felt that there was a lack of both theory and particularly 'hands-on' praxis in initial teacher education and continuing professional education in relation to inclusion and PE. Teachers appear to be comfortable with inclusion; however, the word "challenge" emerged as a concern in relation to interviewees' experiences. This study has implications for more appropriate theoretical and experiential learning in both initial teacher education and continuing professional development for PE teachers to facilitate quality inclusion for students with disabilities.
\end{abstract}

Keywords: inclusion; disability; initial teacher education; continuing professional development; qualitative approach

\section{Introduction}

There has been a global shift towards more inclusive educational systems internationally, particularly in the last 30 years (UNESCO, 1994; WHO, 2011). Hence, informed by this development, Irish Government policy has aimed to provide an inclusive educational environment for all individuals (NCSE, 2013). In the Irish context, a considerable body of legislation has been enacted since the 1990s, with consequences for the education of students with disabilities. These include the Education Act 1998, the Equal Status Act 2000 and the Education for Persons with Special Educational Needs Act (EPSEN) 2004, which to date is not fully enacted. Similarly, The Teaching Council of Ireland (established 2006), The National Council for Special Education (established 2003) and the National Council for Curriculum and Assessment (established on a statutory basis 2001) have driven the agenda of inclusive education for students with disabilities from policy perspectives. However, these policy objectives, as reflected in inclusive practice, have yet to be fully entrenched in Irish schools (Shevlin, Winter, \& Flynn, 2013). The educational context of inclusion in relation to disability means educating students with disabilities in a regular educational setting whereby their needs are met (Tant \& Watelain, 2016). For the purpose of this study this definition of inclusion is adhered to.

Additionally, the term 'special educational needs' which is widely used in the Irish educational context, is defined in the EPSEN Act 2004 and pertains to students with disabilities. Special educational needs (SEN) means,

in relation to a person, a restriction in the capacity of the person to participate in and benefit from education on account of an enduring physical, sensory, mental health or learning disability, or any other condition which results in a person learning differently from a 
person without that condition and cognate words shall be construed accordingly

(Government of Ireland 2004, p.6).

Currently, most children with disabilities attend mainstream schools, with less "than 1 per cent of students in Ireland attending a special school" (NCSE, 2013, p. 113).

Despite identified challenges it has been generally accepted that teachers play a major role in facilitating inclusive learning and that their knowledge, skills and attitudes are central to this process (EADSNE, 2010; 2012; Shevlin, Winter, \& Flynn, 2013). Likewise, the essential role of PE teachers in facilitating quality inclusion with students with disabilities in PE is documented. Again issues of knowledge and skill have been identified as integral to this process (Morley et al., 2005; Vickerman \& Coates, 2009; Hodge, Lieberman, \& Murata, 2012).

\section{A need for qualitative research on physical education and inclusion}

A lack of in-depth qualitative research, in the area of PE and inclusion has been highlighted (Block \& Obrusnikova, 2007; Ko \& Boswell, 2013: Campos, Ferreira, \& Block, 2015). Additionally, Block and Obrusnikova (2007) indicated that recent attitude and perceived competency related research had focused on undergraduate PE teachers, identifying a need for more research amongst practising PE teachers.

Furthermore, they felt that it was particularly essential to investigate the impact of in-service training or continuing professional development and support on the attitudes of practising PE teachers. In this context, Meegan and MacPhail (2006, p. 80) noted that "both quantitative and qualitative research on teachers' perceptions of teaching students with special educational needs in PE in Ireland is very limited". They particularly highlighted the lack of any large scale in-depth qualitative study (Meegan \& MacPhail, 2006).

Since the Meegan and MacPhail study in Ireland the National Council for Special Education (NCSE) has published a series of Research Reports and policy advice papers e.g. NCSE, 2006; NCSE, 2013, which have expanded our knowledge of the development of inclusive practices in primary and post-primary schools to a considerable degree and from a range of perspectives, i.e. teachers, students, parents and policy makers. However, our knowledge of inclusive PE practices, specifically from teachers' perspectives at post-primary level, is virtually non-existent in this context. Given this increased movement towards inclusive education nationally (NCSE, 2013; Shevlin, Winter, \& Flynn, 2013) and globally (Bunch \& Valeo, 2009; Hodge et al., 2009), it is crucial to gain an insight into PE teachers' real-life experiences of the phenomenon.

\section{PE teachers' experiences of and perspectives on inclusion:}

In the past, negative attitudes and perceived lack of competence amongst PE teachers appear as obstacles to inclusion in general PE (Sherrill, 1994; Vickerman \& Coates, 2009; Petkova, Kudlácek, \& Nikolova, 2012). Furthermore, Tant and Watelain (2016) in their systematic review spanning 40 years (1975-2015), found that teachers' perceived competence was the factor that most strongly predicted teacher attitude, i.e. the greater the perceived competence, the more positive the attitude. Nevertheless, some studies did show teachers having a positive concept or at least a positive educational philosophy of inclusive practices. For instance, Hardin (2005) and Hodge and colleagues (2009) found that the teachers they interviewed had both positive and negative attitudes towards inclusion. However, participants in both studies supported the concept of inclusion. The Hodge and colleagues (2009) study explored the views of nine experienced high school PE teachers and found the teachers felt ineptly prepared or lacked support or resources to successfully teach students with more severe disabilities. Despite this, the teachers were motivated by a sense of professional responsibility within the school and also by a larger societal influence. Ko and Boswell (2013, p. 230) presented similar findings in relation to teachers' perceptions being "overwhelmingly positive". Furthermore, teachers' attitudes towards support and collaboration with special educational needs assistants or teaching assistants is generally favourable (Tant \& Watelain, 2016). However, this is compromised by the special needs assistants' lack of knowledge in the specific area of inclusive PE 
(Vickerman \& Blundell, 2012; Pederson, Cooley, \& Rottier, 2014). In the Irish situation, Meegan and MacPhail (2006) investigated the relationship between four specific types of special educational needs and the selected attributes of gender, academic preparation and previous experience. Data from questionnaires distributed to PE teachers indicated that the majority of teachers surveyed have taught students with special educational needs in their classes. Attitudes towards students with specific learning disabilities, emotional/ behavioural disorder and mild to moderate mental impairment were generally undecided. Conversely, teachers' attitudes towards inclusion and students with moderate to severe mental impairment were found to be unfavourable.

\section{Professional Development for teachers}

The European Commission (2013) has highlighted the need to ensure that teachers have the essential competencies they require. To this end they have identified the need to ensure initial teacher education is of the highest quality combining both components of knowledge and skill development and also providing serving teachers with opportunity to continually develop and extend their competencies throughout their careers. The professional learning continuum formulated by Feiman-Nemser (2001), comprising of a pre-service, an induction and a continuing professional development phase is used extensively in teacher education. Similarly, The Teaching Council of Ireland (2011) posits three main stages of learning; initial teacher education, induction and continuing professional development. The National Council of Special Education (NCSE, 2013) emphasizes the need to develop competencies in the areas of attitude, skills, knowledge and understanding required for teachers during their initial and continuing professional development.

Despite official commitments to inclusive models of education, both internationally (Vickerman \& Coates, 2009) and in the Irish context (Meegan \& McPhail, 2006; Crawford, O'Reilly, \& Flanagan, 2012) it would appear that many PE teachers felt they lack adequate professional development in the area. Both at initial and continuing professional phases, PE teachers felt that opportunities focusing on their development as inclusive practitioners were limited, as were opportunities for inclusive strategies (Morley et al, 2005; Ko \& Boswell, 2013; Qi, Wang, \& Ha, 2017). Deriving from their systematic review, Tant and Watelain (2016) identified quality initial teacher education and continuing professional development as central to inclusion. Hence, this particular study sought to examine in-depth the experiences of PE teachers in Ireland in this regard.

The following research questions guided this study:

- What are PE teachers' experiences of inclusion in relation to their sense of competency and initial teacher education?

- What are PE teachers' perspectives on inclusion in the Irish context?

- What are PE teachers' continuing professional development requirements for the future to support inclusion?

\section{Theoretical Framework}

Theoretically, this study is informed by sociocultural principles (Vygotsky, 1978). Sociocultural views consider the bi-directional interaction between the individual and the environment as central to learning. This perspective attempts to portray the "dynamic contexts in which, and the process through which, learning and development take place" (De Valenzuela, 2007, p. 280). In this study the learning interaction between the teacher and student is interpreted as a social process in the Irish cultural context. Similarly, Quennerstedt and colleagues (2014) applied sociocultural theory to explore aspects of learning in PE. In their research learning is viewed as a continuous interaction between students, teachers and cultural/ institutional aspects of the teaching and learning situation. More recently, Qi and colleagues (2017) explored the perceptions of Hong Kong PE teachers on the inclusion of students with disabilities based on Vygotsky's social constructivism theory. They interpreted the theory as learning processes influenced by social interaction using three concepts, 
zone of proximal development (ZPD), inter-subjectivity, and enculturation. The three concepts highlighted resonate within this study and will be drawn upon in the interpretation of the findings.

\section{Methodology}

\section{Research Design}

The research design chosen for this qualitative study comprises of a multiple-case study approach (Punch \& Oancea, 2014). In his work, Stake (2014) advocates the use of the case study in educational research, highlighting particularly the practice of naturalistic, real-life case studies to give teachers' experiences a voice. Furthermore, the choice of study design was also influenced largely by the nature of the research questions (Yin, 2014; Thomas, 2011). Findings from this current study form part of a larger in-depth exploration of inclusion of students with disabilities in PE, where the voices of all stakeholders are explored. Ethical approval was granted by the Social Research Ethics Committee (SREC) at University College Cork, Ireland.

\section{Participants}

This research was based in four mainstream post-primary schools. Data was garnered from seven practising PE teachers working with students with disabilities within these schools, offering a richness of experiences. The sampling strategy for this research consisted of non-probability, purposive sampling (Patton, 1990; Flyvbjerg, 2006). Maximum variation within the selection criteria was selected. The motivation behind qualitative research is to purposefully select participants most suited to answer the research questions (Creswell, 2009). Selection criteria for participation were as follows: (a) the participant was a fully qualified PE teacher (b) the participant had at least three years teaching experience, and (c) the participant was teaching a student with a diagnosed disability in a main stream PE setting. In this study all the participants teach students with disabilities in general PE. Background data of PE teachers and schools are presented in Table 1. Participants were drawn exclusively from schools in the Republic of Ireland.

Table 1. Background data of PE teachers and school type

\begin{tabular}{|c|c|c|c|c|}
\hline Teacher & Gender & Experience (years) & University & School type and size \\
\hline Noel $^{*}$ & $\mathrm{M}$ & 22 & A & $\begin{array}{l}\text { School one is a co-ed community school, Rural } \\
\text { town, } 1000 \text { students approx., } \\
5 \text { PE teachers in the school. }\end{array}$ \\
\hline Gina* & $\mathrm{F}$ & 7 & B & \\
\hline Mona* & $\mathrm{F}$ & 10 & B & $\begin{array}{l}\text { School two is a DEIS, co-ed community school, } \\
\text { Urban suburb, } 250-260 \text { students, } 2 \text { PE teachers } \\
\text { in the school, deaf unit. }\end{array}$ \\
\hline Carly* & $\mathrm{F}$ & 6 & $\mathrm{C}$ & \\
\hline Jane $^{*}$ & $\mathrm{~F}$ & 27 & $\mathrm{D}$ & $\begin{array}{l}\text { School three is an all- girls, religious secondary } \\
\text { school, Urban, } 220 \text { students, } 1 \text { PE teacher in the } \\
\text { school, Autism Spectrum Disorder (ASD) unit. }\end{array}$ \\
\hline $\mathrm{Ed}^{*}$ & $\mathrm{M}$ & 28 & $\mathrm{D}$ & $\begin{array}{l}\text { School four is an all- boys, DEIS, religious } \\
\text { secondary school, Urban, } 235 \text { students, } 3 \text { PE } \\
\text { teachers in the school, ASD unit. }\end{array}$ \\
\hline Sam $^{*}$ & M & 4 & C & \\
\hline
\end{tabular}

*= pseudonym used; DEIS: Delivering Equality of Opportunity in Schools

\section{Data Collection}

The data collection method utilised was face to face, in-depth, individual, semi-structured interviews. This method is widely used in educational research (Kvale \& Brinkmann, 2009; Punch \& Oancea, 2014). It was considered the most apposite for this study having "set questions and prompts 
for discussion, but (also) having in-built flexibility to adapt to particular respondents and situations" (Punch \& Oancea, 2014, p. 184). An interview aims at "nuanced accounts of different aspects of the interviewee's life world; it works with words and not with numbers" (Kvale \& Brinkmann, 2009, p. 30). The data collection questions derived from the three main research questions outlined earlier. These questions were guided by an extensive literature review, the research focus and the theoretical framework (Vygotsky 1978) of the study. Additionally, the works of Morley and colleagues (2005), Hodge and colleagues (2009), and Ko and Boswell (2013) have influenced the selection of specific questions. The seven participants were interviewed for approximately 45-60 minutes each. Semi structured interviews were recorded and transcribed verbatim, following pilot interviews which informed the interview process.

\section{Data analysis}

Data analysis was guided by Miles, Huberman and Saldana's (2014) approach, who view qualitative data analysis as three concurrent flows of activity, data condensation, data display, and conclusion drawing and verification (Miles, Huberman, \& Saldana, 2014, p. 12). Data were inputted to the computer qualitative data analysis software NVivo 11. All data were read and re-read several times, then first cycle or initial coding was applied to the data chunks. Second cycle coding or selective coding was then used to organise the data from the first cycle codes into categories. These categories were then collated into themes. Analytical memos were used by the researchers to weave together the codes and categories (Miles, Huberman, \& Saldana, 2014). From the analysis, categories and themes emerged in two ways. Firstly, categories emerged which were guided by the research questions, secondly, other unanticipated categories emerged inductively from the participants own experiences and expression. Peer debriefing and member checks were employed to enhance credibility of the study (Bryman, 2012).

\section{Results}

Analysis was conducted in relation to the experiences and perspectives of the research participants. First cycle coding identified twenty-five codes. These were then grouped into ten pattern codes or categories. These ten categories were then placed into two broad main themes decided upon by the authors. The themes are not mutually exclusive. Indeed, there was an overlap occasionally, reflecting the complexities of the participants lived experiences. The following categories constitute the theme of the lived experience of the PE teacher, shift towards inclusion, knowledge on government policy on inclusion, influences on teachers' attitudes toward disabilities, perspectives of teachers toward inclusion, information and resources, and lastly, skill acquisition and student health. Secondly, within the theme of the pathway of lifelong learning for the inclusive PE teacher, the following categories emerged, continuing professional development, initial teacher education, and, perceived competency and support. These two themes and their attendant categories frame the presentation of findings.

\section{The lived experience of the PE teacher}

In this section the findings reflect the everyday lived experiences of the PE teacher on inclusion. The findings are presented from the teachers' own words using direct quotes.

\section{Shift towards inclusion}

All seven PE teachers indicated that they have seen an increase in the number of students presenting with disabilities.

I suppose we have more children with, we will say obvious disabilities now. I mean a lot of parents now are moving away from the special school situation, and want their child to go to a mainstream school. And so therefore, I think all schools are .... I would say probably have students with special educational needs yeah [Jane]. 
In addition, Ed agreed, 'I would definitely say there are more students coming in (with disabilities) and it's a challenge'.

\section{Knowledge on government policy on inclusion}

When participants were questioned on their knowledge regarding the Irish government's policy thrust of inclusion and their views on it, most were not familiar with the policy per se, but felt inclusion was working in the school. The teachers from school one to three all gave similar responses, such as Mona and Noel, 'I wouldn't be overly familiar with it. I know it's there' [Mona] and 'I am not aware of the policy other than the fact that it seems to be happening. Our school seems to be getting on with it and it seems to have the resources to support it' [Noel].

However, both teachers in school four appeared more knowledgeable, citing the 1998 Education Act, with Sam also referring to the EPSEN Act, 'Well I'm familiar with the 1998 Education Act. However, a failure to implement in full the 2004 EPSEN Act, I suppose remains a concern which needs to be addressed by Government alright'.

The very pertinent point on the partial implementation of the EPSEN Act, highlighted by Sam leads to the issue of Individual Education Plans (IEP's). We were keen to discover if the participating teachers in the schools were familiar with IEPs and if they currently use them. As previously witnessed the teachers from school one to three presented similar findings. On the whole, they do not use IEPs in physical education. The PE teachers in school four seemed most familiar with the use of IEP's in PE. This was particularly true of Sam, as he also fulfils the role of ASD teacher within the school. Interestingly, Noel from school one was familiar with the use of IEP's when he worked in the UK but stated that he does not use them in his current school in Ireland.

\section{Influences on teachers attitudes toward disabilities}

Participating PE teachers were asked if they knew people with disabilities outside of their school setting and if they felt that this has influenced their attitude towards disability. Both Noel and Sam had childhood experiences which have influenced them.

I grew up playing table tennis with wheelchair users. I was young at the time but I suppose it made me aware of the challenges that some people face. It was made perfectly clear to me at that early stage in my life that they resented pity and being treated differently to anyone else. Everyone should be treated the same [Noel].

Yes, when I was growing up my next-door neighbour had cerebral palsy, but competed and won medals at the Paralympics. Therefore, from an early age it was clear to me that disability was not an obstacle to participation in sport. And I suppose to some degree that influenced me [Sam].

However, Carly who had little interaction as a child with people with disabilities expressed the fear she previously held: Yeah because I remember when I was younger I was terrified of people (with disabilities) I remember my friend's cousin who was severe special needs at parties and she was there and I didn't know what to expect [Carly].

Looking through the sociocultural lens, the effect of inclusion on peers without disabilities elicited a mostly positive response from participants. A common thread expressed by the participating teachers was the notion of 'acceptance' of difference and the benefit of this for students in general, 'Here our students accept people for who they are and they don't seem to be too bothered by the differences' [Mona]. Nonetheless, Noel, Carly and Jane highlighted an issue in relation to competitive games.

I have experienced groups who have not been willing to include students with special educational needs. Where a student with special educational needs would have been seen as detracting from their own experiences and enjoyment in the class .So that's not an easy situation to manage when you don't have the support of the group you are teaching [Noel]. 
However, the broad response of participating teachers in relation to the effect of inclusion on peers without disabilities was encouraging.

\section{Perspectives of teachers toward inclusion}

Overall the interviewees' interpretation of the school's view towards inclusive practice was very positive: The school will try and include all students [Mona] and for me it just hasn't been an issue in any way, every student has the right to an education. That seems to be our (the school's) line [Noel].

Delving deeper into the participants' own perspectives, revealed issues relating to differentiation and levels of ability. Some teachers felt that students presenting with more moderate to severe type general learning disability may not be suitable in a mainstream school setting, such as, 'we have one student now in $x$ year as I say that really, I feel we are not serving her needs here' [Jane]. Similarly, 'it's very difficult for a child with moderate learning difficulty to be in a mainstream school' [Carly].

On the whole, however, participating PE teachers in this study indicated an overall positive perspective towards inclusion.

\section{Information and resources available in relation to disability}

It was clear from the interviews that PE teachers felt that their respective schools provided satisfactory information and files on each student with a disability. For the most part, participating teachers felt that they can access background information in relation to the students with disabilities; however, the information is not PE specific. Noel said, 'We have complete support from management, special educational needs department, I 've never felt wanting for anything really, only information and specialist help' [Noel]. Likewise, Gina articulated the following, 'But physical education wise you wouldn't get a huge amount of information, it's more academic, and it's more the type of disability they have. How they are performing academically, and what's their attendance like' [Gina].

Most participating teachers felt that the specialised, adapted PE equipment in their schools could be improved. School two has a specialised sound system for the students who are hard of hearing, which Carly felt works well as the students 'can pick up just our voice through all the noise'. School four has specialised equipment for students with ASD, 'a lot of the stuff is sensory stuff, is relevant to the ASD lads' [Ed].

\section{Skill acquisition and student health}

Whilst not the focus or indeed within the scope of this study, the area of student health emerged as a concern. Firstly, fundamental movement skills (FMS) and fitness levels of all students were voiced as an issue, 'I think we take everybody coming into first year as having a basic level of your throwing and your catching, your fundamental skills. But I don't think they have them' [Gina] and, 'I mean there are some students they come in, they are already unfit at twelve years of age, and you can see it going steadily downhill' [Jane].

Secondly, both PE teachers in school four identified the issue of anxiety amongst their students with disabilities, particularly those presenting with ASD.

What I find with the students, first of all that when they come into first year the students with disabilities, especially the ASD students, is that they are nervous about PE. With some of them I get the impression that they've done very little sport maybe at primary school or maybe at home [Sam].

\section{The pathway of lifelong learning for the inclusive PE teacher}

The professional development pathway of the inclusive PE teacher is offered in this section. The categories of continuing professional development, initial teacher education, perceived competency 
and support are presented. Again the findings are depicted in the teachers own words using direct quotes.

\section{Continuing professional development}

Most participating teachers in this study did not have experience of continuing professional development specific to inclusive PE or Adapted Physical Education. However, they did have experience of special educational needs continuing professional development in general, 'So, I've had that training (special education), not specific to $\mathrm{PE}^{\prime}$ [Jane] and, 'yes (CPD) but in relation to Special Ed... No, not in relation to PE' [Gina].

Sam was the only teacher who had attended a practical workshop specific to adapted physical education: on a practical level, I did attend a workshop that would have been about I'd say a year or maybe two years ago, and that was autism specific in relation to PE [Sam].

This would indicate that there is a lack of continuing professional development specific to inclusive PE. All teachers in this study expressed an interest in participating in continuing professional development specific to inclusive PE. They felt that there is a need for it currently, 'like I would say if you asked any PE teacher, they would say that they don't know enough about (adapted $\mathrm{PE})^{\prime}$ [Gina]. The type of the continuing professional development desired was typically of a practice based workshop rather than a theoretical one, 'for me personally during the school day which isn't ideal, yeah, a workshop would be good, a practical workshop' [Ed].

The notion of continuing professional development during school time, emanated strongly from the two most experienced teachers. Schools one, two and four have two PE teachers or more, whereas school three has just one. In this school, the PE teacher stated, 'not a manual, no, people are very busy in their lives, the manual will get put somewhere, either I'm released from my teaching duties to go to a workshop, or that a workshop happens in the school' [Jane]

Regarding the notion of a community of practice (Lave and Wenger 1991; Wenger 1998), teachers spoke about the idea of informally interacting or 'bouncing ideas' off each other concerning various PE issues. Participants indicated that it is uncommon for PE teachers to meet outside of the school day on a professional level. A number of the PE teachers referred to the positive engagement and interaction with student PE teachers during their initial teacher education stage of professional teaching practice. Jane in particular found this engagement useful as she is the only PE teacher in her school.

I'd say my most engaging really is with students that are doing their teaching practice with the local University, and I mean they are probably way ahead of where I am really because they are being trained in that (APE) now. And I would always try and learn anything I can from them as well [Jane].

\section{Initial teacher education}

As to be expected the most experienced teachers, Noel, Jane and Ed did not receive any formal training in adapted physical education, 'I can't remember any formal training (in adapted physical education) at all' [Noel]. Jane and Ed completed their degrees during the nineteen eighties and Noel during the nineteen nineties. Carly could not recollect a module on adapted physical education even though she is a recent graduate and the particular University she attended does offer training in adapted physical education.

I'd say maybe a week, I don't remember it (adapted physical education) I don't remember doing a module in it. No, but as I say we were the first year but I know they have since I

know they do wheelchair basketball tournaments and stuff like [Carly].

Gina and Mona attended the same university and both completed one module on adapted physical education. As part of the adapted physical education module Gina attended a residential setting and planned physical activities for the individuals there. However, both felt it was not adequate to meet their current needs, 'my primary degree definitely not' [Mona]. 
No - some were severely intellectually and physically... they had physical needs, so you know I suppose they wouldn't be in a school setting. And so, classes, so people did get a good experience, but I suppose it wasn't like a school setting either [Gina].

Sam is the most recent graduate, albeit a mature student. He portrays the strongest image of his initial teacher education in relation to inclusion and also of the infusion aspect throughout all his modules studied. The infusion aspect refers to cognisance of differentiation throughout all modules rather than stand-alone modules on disabilities.

Yes, during the course of studying for my degree, I studied modules on adapted physical activity; this was mandatory and very practical. There can never be enough training to prepare teaching students with disabilities; however, the training I received provided a

practical foundation for working with students with disabilities. Also during the course of the four-year degree, while studying various sports, we were regularly reminded to be cognisant of developing a plan for including students with disabilities [Sam].

Nonetheless, it would appear that the majority of PE teachers in this study feel that their initial teacher education was inadequate for their current needs to practice inclusively in physical education.

\section{Perceived competency and support}

Perceived competency in the context of this study is a subjective construct pertaining to the participating teachers' feelings regarding their knowledge, skills and attitudes towards inclusive PE. For the most part teachers appear to be comfortable with inclusion; however, the word 'challenge' emerged from a number of the interviewees, 'It's (inclusion) challenging but I kind of try and take it on as much as I can' [Mona]. Noel commented, 'I have never felt uncomfortable in my teaching. Including all students in every class can be challenging whether they have a specific need or not. Differentiated work is part and parcel of the daily routine'. Whereas Gina stated, 'I think it (inclusion) is hard in a PE setting, especially when its skill based, I find it yeah quite challenging at times'.

PE teachers' experiences of working with special needs assistants or teaching assistants, as a support was varied. Most were positive albeit with a number of issues and concerns emerging. Both teachers in school four presented an encouraging account of their experiences with special needs assistants as a support in physical education class. Jane in school three presented a contrasting view, 'mixed, very mixed, I suppose you live and learn kind of a situation, people (special needs assistants) can get into bad habits, and very hard to break bad habits'. She felt that some special needs assistants have developed poor habits in relation to their involvement and their own attire for a practical PE class. The teachers in school two presented slightly different views. Carly was very positive. Whereas Mona, whilst finding the special needs assistant interaction helpful, favoured peer assistance as a more inclusive strategy in PE, 'I think if they (students with a disability) work too much with the adults they don't get the interaction of working with other students'. Likewise, the PE teachers in school one presented a varied perspective. Noel's experience was positive with an addendum relating to the individual special needs assistant. Interestingly, Gina found the special needs assistant support good in other subjects but not in PE.

In summary, participating teachers felt that there has been an increase in the number of students presenting with disabilities in their lived experience. Most teachers seemed unfamiliar with the government's movement towards inclusive policy but felt that inclusive practices were happening in their schools. Additionally, teachers stated that knowing people with disabilities has influenced their attitude towards disability. A broadly positive response emanated from teachers in relation to the effect of inclusion on peers without disabilities. Participating PE teachers indicated an overall positive perspective towards inclusion with some caveats. Whilst teachers expressed overall satisfaction in relation to information and resources available, they felt this information is not PE specific. 
Additionally, the issue of student health emerged as a concern, particularly in relation to issues of poorly developed FMS, fitness levels and anxiety.

Furthermore, all teachers felt that there is a lack of continuing professional development specific to inclusive PE and the majority felt that their initial teacher education was inadequate to meet their currents needs. The word 'challenge' emerged from a number of interviewees when questioned on perceived competency and inclusion.

\section{Discussion}

The discussion will explore the key research findings in the context of the literature reviewed in the article, under the following headings.

\section{Policy-practice chasm}

Consistent with international (WHO, 2011; EADSNE, 2012) and national (NCSE, 2013) trends, participating PE teachers in this study have observed an increase of students presenting with disabilities in their general educational settings. Existing Government policy (NCSE, 2013) and the EPSEN Act, albeit partially implemented (Government of Ireland, 2004), recommends educating students with disabilities in an inclusive environment (Smyth et al., 2014). Whilst most of the PE teachers were not familiar with the intricacies of the policy momentum per se, they felt that inclusion "was happening" in their schools. However, the fact that the EPSEN Act 2004 has only been partially implemented, due to financial constraints, was highlighted by Sam as a concern. Arising from this is the issue around non-statutory individual education plans. A legal entitlement to an individual education plan does not currently exist for students with special educational needs and will not come into effect until the appropriate sections of the EPSEN Act are commenced by ministerial order (Department of Taoiseach, 2016). Without this commitment, the outlook for the usage of individual education plans is at best, ad hoc in Ireland. This contrasts markedly with countries such as USA, Canada, Australia, New Zealand and the UK, where IEP's are "underpinned by law" (NCSE, 2006).

\section{Viewpoints}

Fundamental to Vygotsky's sociocultural theory, it is the practice of internalisation of social interaction in the construction of knowledge (Vygotsky, 1978; Zapata, 2013). Peering through the sociocultural lens affords an insight into the PE teachers' perspective of disability from a societal, school and a PE class setting. This interlocking triad of viewpoints is guided by the overarching sociocultural framework of this study.

Participants, overall, felt that society has progressed in its perspective towards people with disabilities reflecting a sociocultural shift towards inclusion in society in general. Likewise, the participants' interpretation of their school's views towards inclusive practice was positive. Nevertheless, probing into the everyday practice of inclusion in PE highlighted some issues regarding differentiation and levels of ability. This finding concurs with previous research conducted (Hodge et al., 2009) indicating that students with more severe disabilities were considered to be more challenging to teach.

On the whole, participating PE teachers in this study indicated an overall positive perspective towards inclusion. This finding concurs with recent research conducted (Ko \& Boswell, 2013; Campos et al., 2015) which concluded that teachers showed "positive perceptions of teaching students with disabilities in their general PE classes" (Ko \& Boswell, 2013, p. 236). However, these findings contrast with earlier research, spanning a ten year (1995-2005) review (Block \& Obrusnikova, 2007, p. 116) in which "general PE teachers possess negative feelings toward inclusion". This again evidences a societal move towards inclusion across many aspects of education within the last three decades (UNESCO, 1994; WHO, 2011; Shevlin et al., 2013). 


\section{The pathway of lifelong learning: Inclusion and PE}

In the continuing professional development phase of Feiman-Nemser's (2001, p. 1049) continuum learning to teach the author alludes to the conundrum that "professional development is everybody's and nobody's responsibility". Concurring with previous research (Morley et al., 2005; Ko \& Boswell, 2013; Campos et al., 2015; Qi et al., 2017), teachers in this study felt that PE specific continuing professional development, targeted at helping teachers foster the inclusion of students was lacking. The type of continuing professional development which teachers favoured was of a practical nature and within school time.

Overall, teachers felt that their initial teacher education was inadequate to meet their current needs regarding inclusion and PE. This finding concurs with previous research (Morley et al., 2005; Casebolt \& Hodge, 2010; Campos et al., 2015; Qi et al., 2017). Whilst Crawford and colleagues (2012) found that all four PE initial teacher education providers in Ireland deliver practical and theoretical aspects to their adapted PE modules, the opportunities for undergraduates to gain direct experiential praxis with students with disabilities varied. Accordingly, the authors concluded that "management and coordination of special educational needs appears somewhat ad hoc in each of the Irish institutions" (Crawford et al., 2012, p. 30).

General teachers' views about the quality of their initial teacher education, influences their beliefs about their perceived ability to work with students with disabilities, showing higher levels of efficacy amongst teachers with a positive view of their initial teacher education (Avramidis \& Norwich, 2002; Cochran-Smith \& Zeichner, 2005). Likewise, emanating from Tant and Watelain's (2016) systematic literature review, perceived competency appears to be the factor which most strongly influences a positive PE teacher attitude towards inclusion. For the most part teachers in the current study felt 'comfortable' with inclusion but the word 'challenge' emerged a number of times from the interviewees. Issues of initial teacher education, continuing professional development and teacher competence as highlighted in the European Commission (2013) document still warrant urgent address in the Irish context.

\section{Limitations}

A limitation of this study is the sample size. The sample consisted of four schools and seven PE teachers, which is not representative of the larger population of post primary schools and PE teachers. However, the notion of 'transferability' (from context to context) rather than large scale generalizability tends to be used by qualitative researchers and thus is the situation in this study (Mertens, 2005; Ko \& Boswell, 2013). Another limitation of this study is the one-off interview, a greater insight may have been gleaned through multiple interviews over a period of time or the use of reflective journals by the participants (Hodge et al., 2009).

\section{Perspectives}

The findings of this study possess a number of implications for inclusivity and PE. Firstly, there has been a shift towards the inclusion of students with disabilities in Irish schools (NCSE, 2013). The lived experience of the PE teachers in this study indicated an overall positive attitude and perspective in this context. However, PE specific information and resources for inclusion were voiced as a requirement for teachers. Secondly, the nature of initial teacher education in relation to PE in Ireland should be consistent across providers with a hands-on praxis experience with students with disabilities as presenting in post-primary schools. Thirdly, the participants in the study gave an overall positive view of inclusion, but did find the everyday interactions challenging. In this type of scenario a strong community of practice may support teachers (Wenger, 1998; Crawford et al., 2012). Broadly speaking PE teachers' views towards inclusion are positive with some caveats regarding differentiation and levels of ability.

Fourthly, it was evident that participants in this study felt that continuing professional development specific to PE and inclusion is lacking. The type of continuing professional development voiced by interviewees would be practical in nature and within school time. The Teaching Council of 
Ireland has identified inclusion as one of its national priority areas for continuing professional development (The Teaching Council, 2011, p. 21). However, in reality this does not appear to have transpired for PE specifically. Nevertheless, The Teaching Council of Ireland is currently conducting a development process (2016-2020) in relation to their National Framework for teachers' professional learning known as Cosán (The Teaching Council, 2017). The Irish word for pathway, Cosán, was selected to reflect the idea of professional development learning as an on-going journey. This may address the clearly identified need for and desire among PE teachers for continuing professional development on inclusion amongst practising PE teachers.

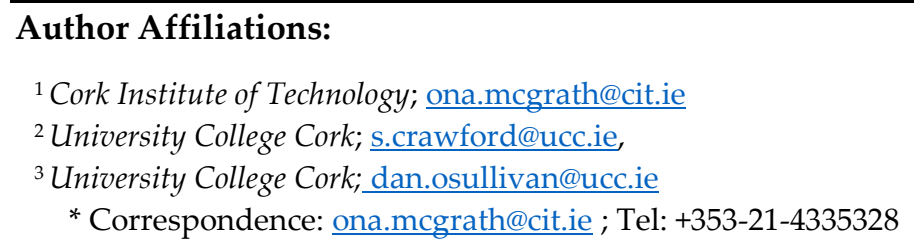

Author Contributions: Conceptualization: Ona McGrath, Susan Crawford and Dan O'Sullivan, Data collection: Ona McGrath, Data analysis: Ona McGrath, Writing, review and editing: Ona McGrath, Susan Crawford and Dan O'Sullivan.

Funding: This research received no external funding

\section{References}

Avramidis, E., \& Norwich, B. (2002). Teachers' attitudes towards integration/inclusion: a review of the literature. European Journal of Special Needs Education, 17(2), 129-147. doi: 10.1080/08856250210129056

Block, M. E., \& Obrusnikova, I. (2007). Inclusion in physical education: a review of the literature from 19952000. Adapted Physical Activity Quarterly, 24(2), 103-124. doi: 10.1123/apaq.24.2.103

Bunch, G., \& Valeo, A. (2009). Inclusive education: emergent solutions. Ontario: Inclusion Press.

Bryman, A. (2012). Social research methods, $4^{\text {th }}$ ed. New York: Oxford University Press.

Campos, M. J., Ferreira, J. P., \& Block, M. E. (2015). Exploring teachers' voices about inclusion in physical education: a qualitative analysis with young elementary and middle school teachers. Comprehensive Psychology, 4(5), 1-9. doi: 10.2466/10. IT.4.5

Casebolt, K., \& Hodge, S. (2010). High school physical education teachers' beliefs about teaching students with mild to severe disabilities. Physical Educator, 67(3), 140-155. Retrieved from https://eric.ed.gov/?id=EJ901223

Cochran-Smith, M., \& Zeichner, K. M. (2005). Studying teacher education: The report of the AERA panel on research and teacher education. Washington DC: AERA.

Crawford, S., O'Reilly, R., \& Flanagan, N. (2012). Examining current provision, practice and experience of initial teacher training providers in Ireland preparing pre-service teachers for the inclusion of students with special education needs in physical education classes. European Journal of Adapted Physical Activity, 5(2), 23-44. doi: 10.1177\%2F1356336X11402260

Creswell, J.W. (2009). Research design: qualitative, quantitative, and mixed methods approaches, $3^{\text {rd }}$ Ed. London: Sage.

Department of Education \& Skills (2016). DEIS: delivering equality of opportunity in schools. Retrieved from http://www.education.ie/en/Schools-Colleges/Services/DEIS-Delivering-Equality-of-Opportunity-in$\underline{\text { Schools-l }}$

Department of the Taoiseach (2016). A programme for a partnership Government. Retrieved from http://www.taoiseach.gov.ie/eng/Work_Of_The_Department/Programme_for_Government/A_Programm e_for_a_Partnership_Government.pdf

De Valenzuela, J.S. (2007). Sociocultural views of learning, in Florian, L. (Ed). The Sage Handbook of Special Education, London: Sage, 280-289.

EADSNE (2010). Teacher education for inclusion: international literature review. Brussels, Belgium: European agency for development in special needs education.

EADSNE (2012). Teacher Education for Inclusion: Profile of Inclusive Teachers. Brussels, Belgium: European agency for development in special needs education.

European Commission (2013). Supporting teacher educators for better learning outcomes. European Commission: Education and training.

Feiman-Nemser, S. (2001). From preparation to practice: designing a continuum to strengthen and Sustain teaching. Teachers College Record, 103(6), 1013-1055. Retrieved from https://eric.ed.gov/?id=EJ640144 
Flyvbjerg, B. (2006). Five misunderstandings about case-study research. Qualitative Inquiry, 12(2), 219-245. doi: $10.1177 / 1077800405284363$

Government of Ireland (2004). Education for persons with special educational needs Act, EPSEN, 2004, Dublin: Stationery Office.

Hardin, B. (2005). Physical education teachers' reflections on preparation for inclusion. The Physical Educator, 62(1), 44-56. Retrieved from https://eric.ed.gov/?id=EJ740122

Hodge, S., Ammah, J., Casebolt, K., LaMaster, K., Hersman, B., Samalot-Rivera, A., \& Sato, T. (2009). A diversity of voices: physical education teachers' beliefs about inclusion and teaching students with disabilities. International Journal of Disability, Development and Education, 56(4), 401-419. doi: 10.1080/10349120903306756

Hodge, S., Lieberman, L., \& Murata, N. (2012). Essentials of Teaching Adapted Physical Education: Diversity, Culture, and Inclusion. United States: Holcomb Hathaway.

Ko, B., \& Boswell, B. (2013). Teachers' perceptions, teaching practices, and learning opportunities for inclusion. The Physical Educator, 70(3), 223-242. Retrieved from https://eric.ed.gov/?id=EJ1018457

Kvale, S. \& Brinkmann, S. (2009). Interviews: learning the craft of qualitative research Interviewing, $2^{\text {nd }}$ ed., London: Sage.

Lave J. \& Wenger, E. (1991.) Situated learning- legitimate peripheral participation, Cambridge University Press.

Meegan, S. \& MacPhail, A. (2006). Irish physical educators' attitude towards teaching students with special educational needs. European Physical Education Review, 12(1) 75-97. doi: 10.1177/1356336X06060213

Mertens, D.M. (2005). Research and evaluation in education and psychology, integrating diversity with quantitative, qualitative and mixed methods, $2^{\text {nd }}$ ed., London: Sage.

Miles, M.B., Huberman, A.M. \& Saldaña, J. (2014). Qualitative data analysis: a methods sourcebook, $3^{\text {rd }}$ ed. London: Sage.

Morley, D., Bailey, R., Tan, J., \& Cooke, B. (2005). Inclusive physical education: teachers' views of teaching children with special educational needs and disabilities in physical education. European Physical Education Review, 11(1) 84-107. doi: 10.1177/1356336X05049826

NCCA (2012). Senior cycle physical education; report on the consultation. Retrieved from http://www.ncca.ie/en/Publications/Reports/SCPE_cons.pdf

NCSE (2006). Guidelines on the individual education process, The Stationery office, Dublin.

NCSE (2013). National Council for special education, supporting students with special educational needs, NCSE Policy Advice paper no.4. Retrieved from http://ncse.ie/wpcontent/uploads/2014/09/Supporting_14_05_13_web.pdf

Patton, M. Q. (1990). Qualitative evaluation and research methods, $2^{\text {nd }} e d$., Newbury Park, CA:Sage.

Pedersen, S. J., Cooley, P. D., \& Rottier, C. R. (2014.) Physical educators' efficacy in utilising paraprofessionals in an inclusive setting. Australian Journal of Teacher Education, 39(10), 1-16. doi: 10.1.4221/ajte.2014v39n10.1

Petkova, A., Kudlácek, M., \& Nikolova, E. (2012). Attitudes of physical education students (last University year) and physical education teachers toward teaching children with physical disabilities in general physical education classes in Bulgaria. European Journal of Adapted Physical Activity, 5(2), 89-98. doi: 10.5507/euj.2012.010

Punch, K.F. \& Oancea, A. (2014). Introduction to research methods in education, $2^{\text {nd }}$ ed., London: Sage.

Qi, J., Wang, L., \& Ha, A. (2017). Perceptions of Hong Kong physical education teachers on the inclusion of students with disabilities. Asia Pacific Journal of Education, 37(1), 86-102. doi: 10.1080/02188791.2016.1169992

Quennerstedt, M., Annerstedt, C., Barker, D., Karlefors, I., Larsson, H., Redelius, K., \& Ohman, M. (2014). What did they learn in school today? A method for exploring aspects of learning in physical education. European Physical Education Review, 20(2) 282-302. doi: 10.1177/1356336X14524864

Sherrill, C. (1994). Adapted physical activity pedagogy: principles, practice and creativity in Yabe, K., Kusano, K. \& Nakata, I. (Eds.) Adapted Physical Activity: Health and Fitness, Tokyo: Springer- Verlag.

Shevlin, M., Winters, E., \& Flynn, P. (2013). Developing inclusive practice: teacher perceptions of opportunities and constraints in the Republic of Ireland. International Journal of Inclusive Education, 17(10), 1119-1133. doi: 10.1080/13603116.2012.742143

Stake, R.E. (2014). Comparison: telling its story, not it's measurements: representing the quality of education, public lecture, Mary Immaculate College, University of Limerick, 10 June 2014.

Tant, M., \& Watelain, E. (2016). Forty years later, a systematic literature review on inclusion in PE (1975-2015): A teacher perspective. Educational Research Review, 19, 1-17. doi: 10.1016/j.edurev.2016.04.002

The Teaching Council (2011). Policy on the continuum of teacher education, Maynooth, Ireland: The Teaching Council. 
The Teaching Council (2017). Teacher education: continuing professional development. Retrieved from http://www.teachingcouncil.ie/en/Publications/Teacher-Education/Documents/Cosan-DevelopmentProcess.pdf

Thomas, G. (2011). How to do your case study: A guide for students and researchers, London: Sage.

UNESCO (1994). The Salamanca statement and framework for action on special needs education. Retrieved from http://www.unesco.org/education/pdf/SALAMA E.PDF

Vickerman, P., \& Coates, J. K. (2009). Trainee and recently qualified physical education teachers' perspectives on including children with special educational needs. Physical Education and Sport Pedagogy, 14(2), 137-153. doi: 10.1080/17408980802400502

Vickerman, P., \& Blundell, M. (2012.) English learning support assistants' experiences of including children with special educational needs in physical education. European Journal of Special Needs Education, 27(2), 143-156. doi: 10.1080/08856257.2011.645585

Vygotsky, L. (1978). Mind in society. The development of higher psychological processes. Cambridge, MA: Harvard University Press.

Wenger, E. (1998). Communities of practice: learning, meaning and identity. Cambridge University Press.

WHO (2011). World Health Organization, World report on disability, Malta: WHO.

WHO (2018). Health topics: disabilities. Retrieved from http://www.who.int/topics/disabilities/en/

Zapata, M. (2013). Substantiating the need to apply a sociocultural lens to the preparation of teachers in an effort to achieve science reform. Cultural Studies of Science Education, 8(4), 777-801. doi: 10.1007/s11422-0139513-8

(C) 2018 by the authors. Submitted for possible open access publication under the terms and conditions of the Creative Commons Attribution (CC BY) license (http://creativecommons.org/licenses/by/4.0/). 